\title{
Adult height in girls with central precocious puberty treated with gonadotropin-releasing hormone agonist with or without growth hormone
}

Mo Kyung Jung, MD', Kyung Chul Song, MD', Ah Reum Kwon, MD', Hyun Wook Chae, MD', Duk Hee Kim, MD, PhD', Ho-Seong Kim, MD, PhD ${ }^{1}$

'Department of Pediatrics, Severance Children's Hospital, Yonsei University College of Medicine, Seoul, ${ }^{2}$ Sowha Children's Hospital, Seoul, Korea
Received: 23 September, 2014 Revised: 9 October, 2014 Accepted: 27 October, 2014

Address for correspondence:

Ho-Seong Kim, MD

Department of Pediatrics,

Severance Children's Hospital,

Yonsei University College

of Medicine, 50-1 Yonsei-ro,

Seodaemun-gu, Seoul 120-752,

Korea

Tel: +82-2-2228-2050

Fax: +82-2-393-9118

E-mail:kimho@yuhs.ac
Purpose: There is controversy surrounding the growth outcomes of treatment with gonadotropin-releasing hormone agonist $(\mathrm{GnRHa})$ in central precocious puberty (CPP). We analyzed height preservation after treatment with GnRHa with and without growth hormone $(\mathrm{GH})$ in girls with CPP.

Methods: We reviewed the medical records of 82 girls with idiopathic CPP who had been treated with GnRHa at Severance Children's Hospital from 2004 to 2014. We assessed the changes in height standard deviation score (SDS) for bone age (BA), and compared adult height (AH) with midparental height (MPH) and predicted adult height $(\mathrm{PAH})$ during treatment in groups received $\mathrm{GnRHa}$ alone $(\mathrm{n}=59)$ or GnRHa plus $\mathrm{GH}(\mathrm{n}=23)$.

Results: In the GnRHa alone group, the height SDS for BA was increased during treatment. $\mathrm{AH}(160.4 \pm 4.23 \mathrm{~cm})$ was significantly higher than the initial PAH $(156.6 \pm 3.96 \mathrm{~cm})(P<0.001)$, and it was similar to the MPH $(159.9 \pm 3.52 \mathrm{~cm})$. In the GnRHa plus GH group, the height SDS for BA was also increased during treatment. $\mathrm{AH}(159.3 \pm 5.33 \mathrm{~cm})$ was also higher than the initial PAH $(154.6 \pm 2.55 \mathrm{~cm})(P<0.001)$, which was similar to the MPH $(158.1 \pm 3.31 \mathrm{~cm})$. Height gain was slightly higher than that in the GnRHa alone group, however it statistically showed no significant correlation with GH treatment.

Conclusion: In CPP girls treated with GnRHa, the height SDS for BA was increased, and the $\mathrm{AH}$ was higher than the initial PAH. Combined GH treatment showed a limited increase in height gain.

Keywords: Central precocious puberty, Gonadotropin-releasing hormone, Growth hormone, Treatment outcome

\section{Introduction}

Precocious puberty is defined as the development of secondary sexual characteristics earlier than two standard deviations of the mean value ${ }^{1)}$. It occurs at least 10 times more frequently in girls than in boys. The clinical manifestations in girls with precocious puberty are breast development before 8 years. Public interest in precocious puberty is gradually increasing because it can cause psychological discrepancies between physical and chronologic age, and it may increase the risks for social problems such as school violence and sexual abuse ${ }^{2)}$. Moreover, precocious puberty can cause a shorter final height due to the early closure of the epiphyses.

Precocious puberty may be classified into two groups, which are central precocious puberty (CPP, also known as true precocious puberty) and peripheral precocious puberty (also known as precocious pseudopuberty). CPP is the result of the precocious activation of the hypothalamic-pituitary-gonadal axis, and the majority of CPP is idiopathic, which 
is commonly treated with gonadotropin-releasing hormone agonists $(\mathrm{GnRHa})^{3)}$.

GnRHa is generally considered standard treatment for CPP. It reduces gonadotropin release selectively and lowers sex steroid hormone secretion to a prepubertal level ${ }^{4)}$. In detail, GnRHa acts via desensitization and down-regulation of pituitary $\mathrm{GnRH}$ receptors and as a result gonadotropin release is gradually inhibited after an initial stimulation 'flare-up' phase ${ }^{5)}$. GnRHa treatment is reported to be effective in postponing pubertal development by slowing the accelerated growth and bone maturation, thus preserving height potential ${ }^{3)}$. However, there is still controversy over the benefits and effects of GnRHa treatment, especially about the preservation of adult height $(\mathrm{AH})^{6)}$.

The aim of the present study was to evaluate the statural growth outcomes in girls with CPP who were treated with GnRHa with or without growth hormone $(\mathrm{GH})$. We analyzed height preservation by assessing the changes in height standard deviation score (SDS) for bone age (BA), and comparing their AHs with their midparental height $(\mathrm{MPH})$ and predicted adult height $(\mathrm{PAH})$ prior to $\mathrm{GnRHa}$ treatment initiation.

\section{Materials and methods}

\section{Subjects}

We retrospectively analyzed the medical records of the 82 girls with idiopathic CPP who were treated with GnRHa and attained their final AHs at the Pediatric Endocrinology Clinic of Severance Hospital from 2004 to 2014. As some of these patients had also received GH treatment, we divided the patients into two groups, one group received GnRHa treatment alone $(n=59)$ and the other group receiving GnRHa plus GH treatment $(n=23)$.

Patients were identified to have idiopathic CPP if they satisfied the classical diagnostic criteria: (1) the onset of breast development (Tanner stage B2 or above) before the age of eight, (2) peak luteinizing hormone (LH) level of above $5 \mathrm{IU} / \mathrm{L}$ in the standard intravenous GnRH stimulation test, and (3) no evidence of hypothalamic-pituitary organic lesions, confirmed by magnetic resonance imaging. Subjects were excluded from analysis if they had any additional conditions that could affect the onset of puberty such as hypothyroidism or congenital adrenal hyperplasia.

\section{Methods}

Subcutaneous injections of GnRHa were administered to the patients at a dose of $75-150 \mu \mathrm{g} / \mathrm{kg}$ every 28 days. Twenty-eight percent of patients (23 of $82 \mathrm{CPP}$ girls) underwent GnRHa and $\mathrm{GH}$ combined treatment. In the GH combined group, patients were treated with subcutaneous injection of $\mathrm{GH}$ at a dose of 0.25 $\mathrm{mg} / \mathrm{kg}$ per week, 6 days weekly. The GH treatment duration was $1.9 \pm 0.99$ years $(0.6-4.1$ years $)$.
We evaluated height, weight, body mass index (BMI) and BA before and after GnRHa treatment. At each evaluation, height was measured three times with a Harpenden stadiometer. The BA was assessed by the Greulich-Pyle method ${ }^{7)}$ by the same observer. Growth parameters such as height, weight, and BMI were expressed as SDS, which was calculated using the Korean children and adolescents growth standard ${ }^{8)}$. PAH was calculated according to the Bayley-Pinneau method ${ }^{9)}$. MPH was defined as the average of the parental heights minus $6.5 \mathrm{~cm}$. AH was measured at the time when growth velocity was less than $1 \mathrm{~cm}$ per year, at least two years after menarche, and when BA was over 15 years. Also, gain of height SDS (difference between AH SDS and initial height SDS for BA), AH-MPH (difference values between $\mathrm{AH}$ and $\mathrm{MPH}$ ), and $\mathrm{AH}-\mathrm{PAH}$ at start (difference between $\mathrm{AH}$ and initial PAH) were analyzed to assess the effectiveness of GnRHa.

The serum levels of LH, FSH were measured by sequential two-step immunoenzymatic assay (Access hLH, FSH Reagent Pack, Beckman Coulter Inc., Brea, CA, USA), and E2 level was measured using a competitive binding immunoenzymatic assay (Access Estradiol Reagent, Beckman Coulter Inc.).

\section{Statistical analysis}

Statistical analysis of the results was performed using IBM SPSS Statistics ver. 20.0 (IBM Co., Armonk, NY, USA). All data was expressed as mean \pm standard deviation, and the paired $t$-test was applied to compare the data. Correlations between parameters were determined using Pearson correlation coefficient analysis. A $P$-value of less than 0.05 was considered statistically significant.

\section{Results}

\section{Auxological characteristics of subjects treated with $\mathrm{GnRHa}$ alone during treatment and at $\mathrm{AH}$}

Chronological age (CA) and BA at the start of GnRHa treatment were $8.7 \pm 0.78$ and $10.2 \pm 1.60$ years, respectively. BA was advanced $1.7 \pm 0.58$ years compared to CA. At the end of treatment, BA was $11.9 \pm 0.54$ years, the difference between BA and $C A$ was $1.3 \pm 0.63$ years, which was lower than the difference at the start of treatment $(P<0.001)$ (Table 1$)$. This result suggested that GnRHa treatment had an effect on postponing bone maturation. Height SDS adjusted for BA was increased during treatment and at $\mathrm{AH}$; it was $-0.4 \pm 0.81$ at the start, $-0.3 \pm 0.80$ at the end of treatment, and $0.3 \pm 0.87$ at final (Table 1, Fig. 1). The difference values from the start of treatment were $0.1 \pm 0.42$ at the end of treatment $(P=0.056)$, and $0.7 \pm 0.82$ at $\mathrm{AH}(P<0.001)$. This result showed that compared to the initial measurements, height SDS for BA increased significantly at final AH, whereas it was not significantly different during GnRHa treatment. AH (160.4 \pm 4.23 $\mathrm{cm})$ was significantly higher than the initial PAH $(156.6 \pm 3.96$ $\mathrm{cm})(\mathrm{AH}-\mathrm{PAH}$ was $3.8 \pm 4.03 \mathrm{~cm}, P<0.001)$, and similar to $\mathrm{MPH}$ 
$(159.9 \pm 3.52 \mathrm{~cm})$ (Table 1. Fig. 2).

\section{Auxological characteristics of subjects treated with $\mathrm{GnRHa}$ plus $\mathrm{GH}$ during treatment and at $\mathrm{AH}$}

$\mathrm{BA}$ at the start of treatment was $10.5 \pm 0.86$ years, which was $1.7 \pm 0.69$ years more than $\mathrm{CA}$, whereas $\mathrm{BA}$ at the end of treatment was $11.9 \pm 0.43$ years, which was $1.2 \pm 0.62$ years more than CA. The difference between BA and CA at the end of treatment was also lower than before treatment, similar to the GnRHa alone group $(P<0.001)$ (Table 2$)$. Height SDS for BA

Table 1. Auxological data in 59 CPP patients treated with GnRHa alone during treatment and at adult height

\begin{tabular}{lccc}
\hline Variable & At start of GnRHa & At end of GnRHa & At adult height \\
\hline CA (yr) & $8.7 \pm 0.78$ & $10.6 \pm 0.76$ & $15.2 \pm 1.53$ \\
BA (yr) & $10.5 \pm 0.86$ & $11.9 \pm 0.54$ & - \\
BA-CA (yr) & $1.7 \pm 0.58$ & $1.3 \pm 0.63$ & - \\
Height (cm) & $136.9 \pm 7.40$ & $147.4 \pm 5.98$ & $160.4 \pm 4.23$ \\
Weight (kg) & $34.3 \pm 6.62$ & $43.4 \pm 7.31$ & $50.4 \pm 5.52$ \\
BMI (kg/m $\left.{ }^{2}\right)$ & $18.2 \pm 2.36$ & $19.9 \pm 2.66$ & $19.6 \pm 1.86$ \\
Height SDS for CA & $1.5 \pm 1.09$ & $1.0 \pm 0.96 a)$ & $0.4 \pm 0.80^{* * *}$ \\
Height SDS for BA & $-0.4 \pm 0.81$ & $-0.3 \pm 0.80$ & $0.3 \pm 0.87^{* * *}$ \\
MPH (cm) & - & $159.9 \pm 3.52$ & - \\
PAH (cm) & $156.6 \pm 3.96$ & $157.1 \pm 3.75$ & - \\
AH (cm) & - & - & $160.4 \pm 4.23$
\end{tabular}

Values are presented as mean \pm standard deviation.

CPP, central precocious puberty; GnRHa, gonadotropin-releasing hormone agonist; CA, chronological age; BA, bone age; BMI, body mass index; SDS, standard deviation score; $\mathrm{MPH}$, midparental height; $\mathrm{PAH}$, predicted adult height; $\mathrm{AH}$, adult height.

${ }^{* * *} P<0.001$ vs. start of GnRHa treatment.

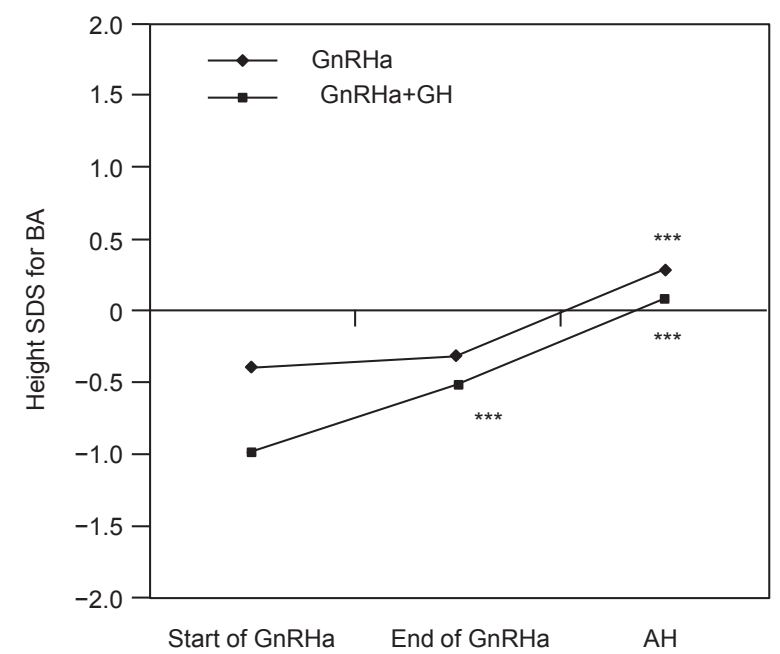

Fig. 1. Changes in height standard deviation score (SDS) for bone age (BA) during treatment in 59 central precocious puberty (CPP) patients treated with gonadotropin-releasing hormone agonist (GnRHa) alone $(\bullet)$ and in 23 CPP patients treated with GnRHa plus GH ( $\mathbf{\square})$. AH, adult height; GH, growth hormone. ${ }^{* *} P<0.001$ vs. start of GnRHa treatment. was also increased during treatment and at $\mathrm{AH}$. It indicated $-1.0 \pm 0.53$ before treatment, $-0.5 \pm 0.82$ at the end of treatment, and $0.1 \pm 1.10$ at $\mathrm{AH}$ (Table 2, Fig. 1). The difference values from the start were $0.5 \pm 0.64$ at the end of treatment $(P<0.001)$, and $1.1 \pm 1.05$ at $\mathrm{AH}(P<0.001)$. This result showed that the height SDS for BA in the GH combined group constantly increased during treatment. AH $(159.3 \pm 5.33 \mathrm{~cm})$ reached $\mathrm{MPH}(158.1 \pm 3.31 \mathrm{~cm})$, and was significantly higher than the initial PAH (154.6 \pm 2.55 $\mathrm{cm})(\mathrm{AH}-\mathrm{PAH}$ was $4.7 \pm 5.04 \mathrm{~cm}, P<0.001)$ (Table 2, Fig. 2).

Table 2. Auxological data in 23 CPP patients treated with GnRHa plus $\mathrm{GH}$ during treatment and at adult height

\begin{tabular}{lccc}
\hline Variable & At start of GnRHa & At end of GnRHa & At adult height \\
\hline CA (yr) & $8.8 \pm 0.59$ & $10.8 \pm 0.51$ & $15.4 \pm 1.23$ \\
BA (yr) & $10.5 \pm 0.86$ & $11.9 \pm 0.43$ & - \\
BA-CA (yr) & $1.7 \pm 0.69$ & $1.2 \pm 0.62$ & - \\
Height (cm) & $133.8 \pm 5.47$ & $146.6 \pm 5.62$ & $159.3 \pm 5.33$ \\
Weight (kg) & $31.2 \pm 4.70$ & $39.7 \pm 6.31$ & $47.8 \pm 6.07$ \\
BMl (kg/m $\left.{ }^{2}\right)$ & $17.3 \pm 1.55$ & $18.4 \pm 2.00$ & $18.0 \pm 4.27$ \\
Height SDS for CA & $0.7 \pm 0.84$ & $0.8 \pm 0.88$ & $0.0 \pm 1.03^{* * *}$ \\
Height SDS for BA & $-1.0 \pm 0.53$ & $-0.5 \pm 0.82 \mathrm{a})$ & $0.1 \pm 1.10^{* * *}$ \\
MPH (cm) & - & $158.1 \pm 3.31$ & - \\
PAH (cm) & $154.6 \pm 2.55$ & $156.0 \pm 3.82$ & - \\
AH (cm) & - & - & $159.3 \pm 5.33$ \\
\hline Val ar & & - &
\end{tabular}

Values are presented as mean \pm standard deviation.

CPP, central precocious puberty; GnRHa, gonadotropin-releasing hormone agonist; GH, growth hormone; CA, chronological age; $\mathrm{BA}$, bone age; $\mathrm{BMI}$, body mass index; SDS, standard deviation score; $\mathrm{MPH}$, midparental height; $\mathrm{PAH}$, predicted adult height; $\mathrm{AH}$, adult height.

${ }^{* * *} P<0.001$ vs. start of GnRHa treatment.

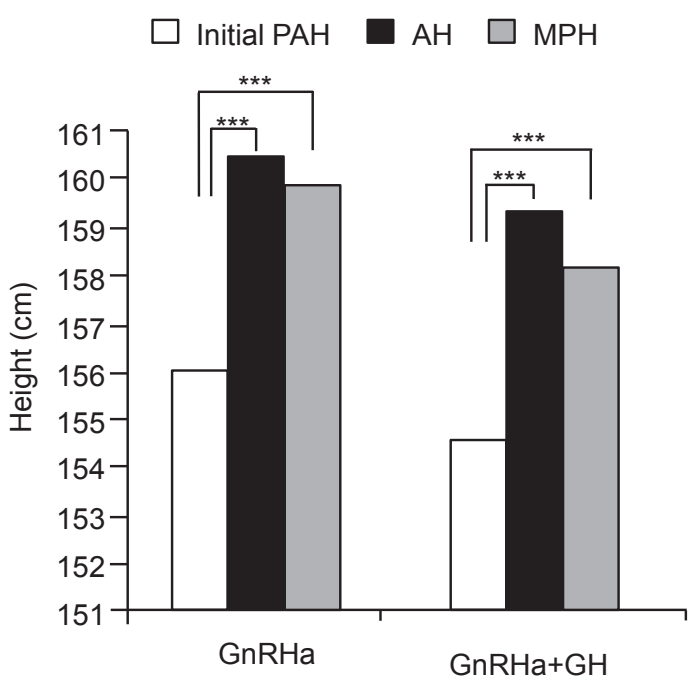

Fig. 2. Initial predicted height, midpatental height and ault height of 59 central precocious puberty (CPP) patients treated with gonadotropin-releasing hormone agonist (GnRHa) alone and in 23 CPP patients treated with GnRHa plus growth hormone (GH). PAH, predicted adult height; $\mathrm{AH}$, adult height; MPH, midparental height. ${ }^{* *} P<0.001$ vs. initial PAH. 


\section{Comparison of growth outcomes between $\mathrm{GnRHa}$ alone group and $\mathrm{GnRHa}$ plus $\mathrm{GH}$ group}

Gain of height SDS (difference between AH SDS and initial height SDS for BA) were $1.0 \pm 0.91$ in GnRHa alone group and $1.2 \pm 0.93$ in GnRHa plus GH group, showing no significant difference between the two groups $(P=0.44)$ (Table 3$)$. It could be explained that the height gain was slightly higher in the $\mathrm{GH}$ combined group, but it was not to be a statistically significant level. In addition, AM-MPH $(0.5 \pm 4.11 \mathrm{~cm}$ in GnRHa alone vs. $1.2 \pm 5.47 \mathrm{~cm}$ in the $\mathrm{GH}$ combined group, $P=0.53$ ) and $\mathrm{AH}-\mathrm{PAH}$ at start $(3.8 \pm 4.03 \mathrm{~cm}$ in GnRHa alone vs. $4.7 \pm 5.06 \mathrm{~cm}$ in the $\mathrm{GH}$ combined group, $P=0.43)$ presented no significant difference between two groups (Table 3).

\section{The correlation between $\mathrm{AH}$ and other auxological factors}

Multiple regression analysis was done to find the factors to influence the growth outcomes on AH SDS (Table 4). The GH combined group was excluded, since GH could be a compounding factor. The AH SDS showed statistically positive effects when the CA at start was younger, MPH was taller. The $\mathrm{BA}$ at start, BA-CA at start, PAH at start, height SDS at start, and duration of treatment had no correlation with the growth outcome.

\section{Time of menarche and growth pattern after cessation of $\mathrm{GnRHa}$}

The time of menarche and the growth pattern after cessation of GnRHa treatment were analyzed (Table 5). Duration from cessation of GnRHa to menarche was $1.0 \pm 0.61$ years. Height increment from cessation of GnRHa to menarche was 5.9 \pm 3.65 $\mathrm{cm}$, whereas the height increment after menarche was 7.1 \pm 2.25 $\mathrm{cm}$. Thus, height increment from cessation of GnRHa to final AH was $13.0 \pm 4.31 \mathrm{~cm}$.

Table 3. Outcome results at final height of the CPP patients treated with GnRHa alone and GnRHa plus GH

\begin{tabular}{lccc}
\hline Outcome & $\begin{array}{c}\text { GnRHa alone } \\
(\mathrm{n}=59)\end{array}$ & $\begin{array}{c}\text { GnRHa plus GH } \\
(\mathrm{n}=23)\end{array}$ & P-value \\
\hline MPH $(\mathrm{cm})$ & $159.9 \pm 3.52$ & $158.1 \pm 3.31$ & 0.03 \\
PAH at start (cm) & $156.6 \pm 3.96$ & $154.6 \pm 2.55$ & 0.03 \\
AH (cm) & $160.4 \pm 4.23$ & $159.3 \pm 5.33$ & 0.34 \\
AH SDS & $0.4 \pm 0.80$ & $0.0 \pm 1.02$ & 0.34 \\
Gain of height SDS & $1.0 \pm 0.91$ & $1.2 \pm 0.93$ & 0.44 \\
AH-MPH (cm) & $0.5 \pm 4.11$ & $1.2 \pm 5.47$ & 0.53 \\
AH-PAH at start (cm) & $3.8 \pm 4.03$ & $4.7 \pm 5.06$ & 0.43 \\
\hline V
\end{tabular}

Values are presented as mean \pm standard deviation.

CPP, central precocious puberty; GnRHa, gonadotropin-releasing hormone agonist; $\mathrm{GH}$, growth hormone; $\mathrm{MPH}$, midparental height; PAH, predicted adult height; $\mathrm{AH}$, adult height; SDS, standard deviation score; $\mathrm{AH}-\mathrm{MPH}$, difference between $\mathrm{AH}$ and $\mathrm{MPH} ; \mathrm{AH}-\mathrm{PAH}$ at start, difference between $\mathrm{AH}$ and initial $\mathrm{PAH}$.

\section{Discussion}

The timing of normal puberty has shown a dramatic decline in age during past centuries. Moreover, the number of patients with CPP has been significantly increased recently. This trend also occurred in Korea with a four- to five-fold increase of CPP in girls over the last five years ${ }^{10)}$. CPP may cause physical and psychological problems for affected girls, so some girls with CPP could be at risk of premature sexual activity, and consequently, sexual abuse. Some reports have shown increased behavioral disturbances, including drug abuse and low socio-culture outcomes ${ }^{11}$. Therefore, proper treatment for CPP is important, not only for individuals but also for society.

GnRHa is generally accepted as the treatment of choice for the improvement of final $\mathrm{AH}$ preservation and also for the reduction of psychosocial problems in CPP patients, however controversy still exists over whether GnRHa treatment improves final AH. Lazar et al. ${ }^{12)}$ found that GnRHa treatment results in little or no increase in final $\mathrm{AH}$ when treatment is initiated after eight years of age. In a study by Pasquino et al. ${ }^{13)}$ in which 87 GnRHa-treated (age, 6.5 years) and 32 nontreated girls with idiopathic CPP (age, 6.8 years), the final AH of treated and nontreated girls were 159.8 and $154.4 \mathrm{~cm}$, respectively. Heger et al. ${ }^{14)}$ also reported on 50 girls with precocious puberty undergoing GnRHa treatment for two years, whose final $\mathrm{AH}$ averaged $160.6 \pm 8.0 \mathrm{~cm}(-0.6 \pm 1.3 \mathrm{SDS})$, which was significantly

Table 4. Multiple regression analysis on AH SDS

\begin{tabular}{lccc}
\hline Variable & Regression coefficient & SE & $P$-value \\
\hline CA at start (yr) & -0.43 & 0.17 & 0.01 \\
BA at start (yr) & 0.09 & 0.07 & 0.21 \\
BA-CA at start (yr) & -0.15 & 0.31 & 0.62 \\
MPH (cm) & 0.05 & 0.03 & 0.05 \\
PAH at start (cm) & 0.03 & 0.13 & 0.83 \\
Height SDS for CA at start & 0.25 & 0.21 & 0.24 \\
Height SDS for BA at start & -0.02 & 0.74 & 0.98 \\
Duration of treatment (mo) & -0.12 & 0.16 & 0.45 \\
\hline
\end{tabular}

$\mathrm{AH}$, adult height; SDS, standard deviation score; SE, standard error; $\mathrm{CA}$, chronological age; $\mathrm{BA}$, bone age; $\mathrm{MPH}$, midparental height; $\mathrm{PAH}$, predicted adult height.

Table 5. Time of menarche and height increment after cessation of GnRHa

\begin{tabular}{lc}
\hline Variable & Mean \pm SD (range) \\
\hline CA at end of GnRHa (yr) & $10.7 \pm 0.70(8.0-12.1)$ \\
BA at end of GnRHa (yr) & $11.9 \pm 0.51(9.0-12.8)$ \\
CA at menarche $(y r)$ & $11.6 \pm 0.90(9.5-13.2)$ \\
BA at menarche $(y r)$ & $12.6 \pm 0.59(11.0-14.0)$ \\
$\begin{array}{l}\text { Duration from cessation of GnRHa to } \\
\text { menarche (yr) }\end{array}$ & $1.0 \pm 0.61(0.0-2.4)$ \\
$\begin{array}{l}\text { Height increment from cessation of GnRHa to } \\
\text { menarche }(\mathrm{cm})\end{array}$ & $5.9 \pm 3.65(0.0-14.3)$ \\
\hline \begin{tabular}{l} 
Height increment after menarche $(\mathrm{cm})$ \\
\hline
\end{tabular} & $7.1 \pm 2.25(1.0-9.0)$ \\
\hline
\end{tabular}

GnRHa, gonadotropin-releasing hormone agonist; $C A$, chronological age; BA, bone age. 
higher than the initial PAH of $154.9 \pm 9.6 \mathrm{~cm}$. Our $82 \mathrm{GnRHa}-$ treated CPP girls achieved final heights that were significantly greater than their pretreatment $\mathrm{PAH}$, which is in agreement with recent studies. In our study, height gain was approximately $3.8 \mathrm{~cm}$ in the GnRHa alone group, while $4.7 \mathrm{~cm}$ in the $\mathrm{GH}$ plus group. In addition, $\mathrm{AH}$ showed a taller tendency when the $\mathrm{CA}$ at start was younger and MPH was taller.

Another issue of this study is whether combined GH treatment improves the growth outcomes of CPP girls. There have been few previous studies about the effectiveness of GH combined therapy on growth outcomes. Pasquino et al. ${ }^{15)}$ and Pucarelli et al. ${ }^{16)}$ showed differences of about $6-8 \mathrm{~cm}$ of height gain on girls with CPP treated with GnRHa plus GH were noted, compared to GnRHa alone. Until the present, there have been no definite conclusions about the growth outcomes of $\mathrm{GH}$-combined treatments. In this study, gain of height SDS and difference between $\mathrm{AH}$ and initial PAH were slightly higher in the GnRHa plus GH group than in the GnRHa alone group in CPP girls, however it showed no statistically significant difference between two groups. These results suggested that combined GH treatment showed a limited increase in height gain. Growth pattern between two groups showed that height SDS for BA was continuously increased during treatment and at $\mathrm{AH}$ in the GnRHa plus GH group, whereas it was increased only at $\mathrm{AH}$ in the GnRHa alone group. This result may result from several reasons. One possibility is that the choice of GH treatment might have a selection bias. Those who have low height potential or attenuated growth velocity might tend to choose the combined GH treatment. Because GH treatment requires the consideration of cost, economic status may be another affecting factor to select the patients treated with GnRHa plus GH. Furthermore, GH treatment duration could be another influencing factor. Cost-effectiveness of combined $\mathrm{GH}$ treatment in patients with $\mathrm{CPP}$ has to be elucidated.

The suppression of the hypothalamic-pituitary-gonadal axis was fully recovered after discontinuation of GnRHa. The average time span from the cessation of treatment to menarche was 1.0 years. Our data about the growth pattern after cessation of GnRHa can be helpful to predict the height increase after discontinuation of GnRHa. In addition, there have been conflicting data regarding the increase in obesity during GnRHa treatment ${ }^{177}$. In present study, the BMI score of girls treated with GnRHa was not significantly increased during treatment. In addition, no adverse effects have been observed.

There were some limitations in our study. GnRHa treatment is not an only single factor to determine the growth outcomes, rather the effects of nutrition, psychosocial status, genetic height potential, and others may influence the outcome. Because GnRHa has recently been accepted as the standard therapy for CPP, GnRHa-untreated patients could not be enrolled in this study. Furthermore, it is considered that further studies about the growth outcomes in CPP girls treated with GnRHa plus GH are required.

In this study about GnRHa treatment in CPP girls, the final AH was significantly higher than the initial height predictions and was close to the MPH. Therefore, it can be concluded that GnRHa treatment is helpful to improve the growth outcomes in girls with CPP.

\section{Conflict of interest}

No potential conflict of interest relevant to this article was reported.

\section{References}

1. Marshall WA, Tanner JM. Variations in pattern of pubertal changes in girls. Arch Dis Child 1969;44:291-303.

2. Kim EY, Lee MI. Psychosocial aspects in girls with idiopathic precocious puberty. Psychiatry Investig 2012;9:25-8.

3. Partsch CJ, Heger S, Sippell WG. Management and outcome of central precocious puberty. Clin Endocrinol (Oxf) 2002;56:129-48.

4. Lahlou N, Carel JC, Chaussain JL, Roger M. Pharmacokinetics and pharmacodynamics of GnRH agonists: clinical implications in pediatrics. J Pediatr Endocrinol Metab 2000;13 Suppl 1:723-37.

5. Conn PM, Crowley WF Jr. Gonadotropin-releasing hormone and its analogues. N Engl J Med 1991;324:93-103.

6. Mul D, Hughes IA. The use of GnRH agonists in precocious puberty. Eur J Endocrinol 2008;159 Suppl 1:S3-8.

7. Greulich WW, Pyle SI. Radiographic atlas of skeletal development of the hand and wrist. 2nd ed. Stanford: Stanford University Press, 1959.

8. Korea Centers for Disease Control and Prevention (KCDC); Korean Pediatric Society, Committee for the Development of Growth Standard for Korean Children and Adolescents. 2007 Korean children and adolescents growth standard: commentary for the development of 2007 growth chart [Internet]. Cheongwon: KCDC, Division of Chronic Disease Surveillance; c2012 [cited 2014 Nov 11]. Available from: http://www.cdc.go.kr/ CDC/info/CdcKrInfo0201.jsp? menuIds=HOME001MNU0004-MNU0007-MNU0025\&fid=28\&q_type $=\& q_{-}$ value $=\&$ cid $=1235$ \&pageNum $=74$.

9. Bayley N, Pinneau SR. Tables for predicting adult height from skeletal age: revised for use with the Greulich-Pyle hand standards. J Pediatr 1952;40:423-41.

10. Kim HK, Kee SJ, Seo JY, Yang EM, Chae HJ, Kim CJ. Gonadotropin-releasing hormone stimulation test for precocious puberty. Korean J Lab Med 2011;31:244-9.

11. Ehrhardt AA, Meyer-Bahlburg HF. Idiopathic precocious puberty in girls: long-term effects on adolescent behavior. Acta Endocrinol Suppl (Copenh) 1986;279:247-53.

12. Lazar L, Padoa A, Phillip M. Growth pattern and final height after cessation of gonadotropin-suppressive therapy in girls with central sexual precocity. J Clin Endocrinol Metab 2007;92:3483-9.

13. Pasquino AM, Pucarelli I, Accardo F, Demiraj V, Segni M, Di 
Nardo R. Long-term observation of 87 girls with idiopathic central precocious puberty treated with gonadotropinreleasing hormone analogs: impact on adult height, body mass index, bone mineral content, and reproductive function. J Clin Endocrinol Metab 2008;93:190-5.

14. Heger S, Partsch CJ, Sippell WG. Long-term outcome after depot gonadotropin-releasing hormone agonist treatment of central precocious puberty: final height, body proportions, body composition, bone mineral density, and reproductive function. J Clin Endocrinol Metab 1999;84:4583-90.

15. Pasquino AM, Pucarelli I, Segni M, Matrunola M, Cerroni F. Adult height in girls with central precocious puberty treated with gonadotropin-releasing hormone analogues and growth hormone. J Clin Endocrinol Metab 1999;84:449-52.

16. Pucarelli I, Segni M, Ortore M, Arcadi E, Pasquino AM. Effects of combined gonadotropin-releasing hormone agonist and growth hormone therapy on adult height in precocious puberty: a further contribution. J Pediatr Endocrinol Metab 2003;16:1005-10.

17. Traggiai C, Perucchin PP, Zerbini K, Gastaldi R, De Biasio P, Lorini R. Outcome after depot gonadotrophinreleasing hormone agonist treatment for central precocious puberty: effects on body mass index and final height. Eur J Endocrinol 2005;153:463-4. 